\title{
Short term impact of smoke-free legislation in England: retrospective analysis of hospital admissions for myocardial infarction
}

\author{
Michelle Sims, research officer, ${ }^{1,2}$ Roy Maxwell, senior analyst, ${ }^{3}$ Linda Bauld, professor of social policy, ${ }^{2,4}$ Anna \\ Gilmore, clinical reader in public health, ${ }^{1,2}$ clinical senior lecturer ${ }^{5}$
}

${ }^{1}$ School for Health, University of Bath, Bath BA2 7AY

${ }^{2}$ UK Centre for Tobacco Control Studies, University of Bath, Bath

${ }^{3}$ South West Public Health Observatory, Bristol BS8 2RA

${ }^{4}$ Department of Social and Policy Sciences, University of Bath, Bath

5 London School of Hygiene and Tropical Medicine, London WC1E 7HT

Correspondence to: A Gilmore, School for Health, University of Bath, Bath BA2 7AY

a.gilmore@bath.ac.uk

Cite this as: $B M J$ 2010;340:c2161 doi:10.1136/bmi.c2161

\section{ABSTRACT}

Objective To measure the short term impact on hospital admissions for myocardial infarction of the introduction of smoke-free legislation in England on 1 July 2007. Design An interrupted time series design with routinely collected hospital episode statistics data. Analysis of admissions from July 2002 to September 2008 (providing five years' data from before the legislation and 15 months' data from after) using segmented Poisson regression.

Setting England.

Population All patients aged 18 or older living in England with an emergency admission coded with a primary diagnosis of myocardial infarction.

Main outcome measures Weekly number of completed hospital admissions.

Results After adjustment for secular and seasonal trends and variation in population size, there was a small but significant reduction in the number of emergency admissions for myocardial infarction after the implementation of smoke-free legislation $(-2.4 \%, 95 \%$ confidence interval $-4.06 \%$ to $-0.66 \%, \mathrm{P}=0.007)$. This equates to 1200 fewer emergency admissions for myocardial infarction (1600 including readmissions) in the first year after legislation. The reduction in admissions was significant in men (3.1\%, $\mathrm{P}=0.001)$ and women (3.8\%, $P=0.007)$ aged 60 and over, and men $(3.5 \%$, $\mathrm{P}<0.01)$ but not women ( $2.5 \% \mathrm{P}=0.38$ ) aged under 60 .

Conclusion This study adds to a growing body of evidence that smoke-free legislation leads to reductions in myocardial infarctions. It builds on previous work by showing that such declines are observed even when underlying reductions in admissions and potential confounders are controlled for. The considerably smaller decline in admissions observed in England compared with many other jurisdictions probably reflects aspects of the study design and the relatively low levels of exposure to secondhand smoke in England before the legislation.

\section{INTRODUCTION}

Numerous studies, including six meta-analyses, ${ }^{1-6}$ have shown that passive smoking increases the risk of coronary heart disease. ${ }^{7}$ Early studies estimated the increased risk at about $30 \%$, but use of marriage to a smoker as a proxy for exposure underestimated exposure. ${ }^{5}$ Recent evidence, based on more accurate biological markers of exposure, suggests the risk could be increased by as much as $60 \%$, similar to that observed in light active smokers. ${ }^{8}$ Although this risk might seem disproportionate, it is consistent with substantial epidemiological and laboratory evidence that the risk of coronary heart disease increases rapidly at low levels of exposure to tobacco smoke. ${ }^{9}{ }^{10}$ Even small exposures have been shown to rapidly increase platelet aggregation and alter endothelial function (with such changes observed within 30 minutes of exposure) and cause other arterial and haemodynamic changes that can increase the risk of coronary heart disease and trigger acute coronary events. ${ }^{7911-13}$ Measures that reduce exposure to secondhand smoke, such as smoke-free legislation, are therefore likely to reduce the incidence of acute coronary events, including myocardial infarction, with almost immediate effect. ${ }^{12}$

Smoke-free legislation has now been introduced in several jurisdictions, and a growing body of evidence links the introduction of this legislation with a reduction in hospital admissions for myocardial infarction and other acute coronary events. ${ }^{14-17}$ The largest impacts have been reported in smaller studies in the United States, ${ }^{18-20}$ with reported reductions in the range of $27-40 \%$, while larger studies have reported more modest reductions: $8 \%$ in the state of New York, ${ }^{21} 13 \%$ in four Italian regions, ${ }^{22}$ and $17 \%$ in Scotland. ${ }^{23}$ Only two studies in New Zealand ${ }^{24}$ and Piedmont, Italy, ${ }^{25}$ found no reduction in overall admissions for myocardial infarction, although the Italian study found an 11\% decline in those aged under 60 .

There is some uncertainty around the extent to which some of these studies have effectively accounted for other factors that might influence patterns of admissions for myocardial infarction. Firstly, admissions for coronary heart disease have been declining across Europe, ${ }^{26-30}$ the US, ${ }^{31}$ and Canada, ${ }^{32}$ and failure to account for this might lead to an overestimation of impacts. Secondly, other factors such as season, flu, and temperature have all been shown to influence the incidence of myocardial infarction with, for example, 
peak admission rates in winter, in spring, and over the Christmas break, and seen in association with high flu rates and low temperatures. ${ }^{33-36}$ Most studies accounted for seasonal differences when estimating impacts of smoke-free legislation on coronary heart disease, either by comparing the same months in a before-after study design ${ }^{223253738}$ or including a predictor for time of year in a regression model. ${ }^{182124}$ Few studies, however, fully accounted for underlying trends in admissions. ${ }^{2122439}$ This is important as trends seem to differ by age group, ${ }^{4041}$ and only one study comprehensively adjusted for other risk factors, including temperature and flu rates. ${ }^{39}$

We addressed all these issues by examining the impact of legislation on hospital admissions for myocardial infarction in England, where all enclosed workplaces and public places, with a few exceptions, became smoke-free on 1 July 2007.

\section{METHODS}

\section{Evaluating impacts of smoke-free England}

\section{Data}

Hospital episode statistics (HES) data provide routinely collected information on all patients who receive care from the National Health Service (NHS) in England. ${ }^{42}$ Each completed record comprises a "finished consultant episode," a period of time a patient spends under the care of one NHS consultant. We extracted data for all finished emergency admission episodes in those aged 18 and over living in England, with an admission date between 1 July 2002 (five years before the legislation) and 30 September 2008 (15 months after the legislation) and a primary diagnosis of ICD-10 (international classification of disease, 10th revision) code 21 (myocardial infarction). ${ }^{43} \mathrm{We}$ retained only the first episode (known as the admission episode) of a patient's stay in hospital because these were more likely to reflect myocardial infarction events that had occurred outside of hospital rather than those occurring as complications of hospital treatment. In line with the ICD-10 code I21 definition of "myocardial infarction specified as acute or with a stated duration of 4 weeks (28 days) or less from onset" ${ }^{\text {"43 }}$ and to avoid duplicate admissions for the same event, we excluded any repeat admissions within a 28 day period. Records missing data on age or sex were excluded from the analysis (less than $0.1 \%$ of records).

\section{Statistical analyses}

Using an interrupted time series design, we developed a segmented Poisson regression model ${ }^{44}$ to test the hypothesis that there was a change in the number of emergency admissions for myocardial infarction immediately after the introduction of smoke-free legislation (that is, from Monday 2 July 2007 onwards). The response variable was the weekly number of admissions, with variation in week length (week 52 was eight days in a non-leap year and nine in a leap year) accounted for by including log number of days as a predictor in the model. The impact of smoke-free legislation, defined as a change in the rate of admissions for myocardial infarction after the legislation, was assessed by including a binary predictor variable in the model with a value of 1 assigned to myocardial infarction events occurring from week 27 of that year (that is, from 2 July 2007 onwards) and 0 before.

An initial exploration of the form of the long term time trend suggested that a linear assumption was appropriate, so we used a linear predictor for time to quantify the underlying downwards trend in admissions. We used 1 July 2002 as the start date, providing five years of pre-legislative data. Various additional predictors were then included in the model to account for variation in admissions for myocardial infarction attributable to factors other than the implementation of smoke-free legislation. ${ }^{33-36}$ To model the temporal fluctuations, we used temperature, flu, week of year, and an indicator variable for the Christmas holidays ( 1 if it is the first or last week in the year and 0 otherwise). Weekly temperatures were the mean of the daily mean surface air temperatures obtained from the Central England Temperature data series. ${ }^{456}$ As preliminary exploration of the data suggested that the effects of temperature might be delayed ${ }^{47}$ we considered two predictors: temperature in the same week as the admission and temperature in the previous week. Weekly flu rates for England and Wales were obtained from the Royal College of General Practitioners' research and surveillance centre, which collects data on consultations for flu-like illnesses from about 100 general practice surgeries, and log transformed before analysis. Temperature and flu rates were considered as linear terms in the model while week of year was included as a cyclic cubic spline to capture any additional seasonal patterns that might be non-linear.

The population estimate for England was included as an offset variable - namely, a predictor variable with a regression coefficient fixed at 1 . This ensures there is a one to one relation between the population size and the number of admissions. Weekly population estimates were obtained by linearly interpolating midyear population estimates for 2002 to 2007 and population projections for 2008 and 2009 provided by the UK's Office for National Statistics.

Models were fitted in R.8.1 using the gam and gamm functions from the library mgcv. ${ }^{48}$ After adjustment for smoke-free legislation, number of days, and population size, we considered the other predictor variables in a backwards selection procedure to identify the best model using the mgcv library's unbiased risk estimator (UBRE), an approximation to Akaikes Information Criterion ${ }^{49}$ to compare candidate models. Models with a lower unbiased risk estimator are preferred. ${ }^{48}$ The suitability of the selected statistical model was assessed with plots of residuals, including an assessment of any remaining serial correlation in the residuals using autocorrelation plots. When necessary, presence of short term autocorrelation was modelled by applying a first order autoregressive $\mathrm{AR}(1)$ structure to the residuals.

To assess differences in the impact of smoke-free legislation among population subgroups, we stratified the 
data by age $(<60, \geq 60)$ and sex and performed separate analyses on each group. We also examined whether there was an increase or decrease in the slope of the trend after the legislation, compared with pre-legislative trends, by adding an interaction term between the binary predictor for smoke-free legislation and the linear predictor for time to the models. To provide further support for the findings we refitted the final models using 16 false dates for smoke-free legislation ranging from January 2005 to January 2007.

\section{Predicting the number of events prevented}

We used the final Poisson regression model to predict the number of emergency admissions for myocardial infarction that were prevented as a result of smoke-free legislation in the first year of implementation. To estimate the number of averted events $N_{e}$ we subtracted the regression based prediction of the number of events from 1 July 2007 to 30 June $2008\left(N_{w}\right)$ from the predicted number of events without the influence of the legislation $\left(N_{\text {ow }}\right)$. If $\beta$ is the estimated regression coefficient for the smoke-free legislation predictor from the final Poisson regression model, $N_{\text {ow }}$ is equivalent to $N_{w}$ / $\exp (\beta)$. The total number of emergency admissions averted will be slightly higher than $N_{e}$ because some of the events result in multiple emergency readmissions to hospital within 28 days, and we excluded these readmissions from the main analysis. Therefore, to predict the total number of emergency admissions prevented we repeated the statistical analysis on a dataset that included readmissions.

\section{RESULTS}

Between 2000 and 2008 there was a notable decrease in the number of emergency admissions for myocardial infarction, a decrease that seems to have accelerated from around 2002 and was greater in older than younger age groups (figs 1 and 2 ). The seasonal pattern observed was consistent with that reported elsewhere, ${ }^{33-36}$ with a peak in admissions over Christmas and early spring, higher rates of admission over winter, and lower rates in summer (fig 3). Indeed the decline each summer was of a similar order of magnitude to the secular decline seen over the six year period studied. Most admissions occurred in men and those aged over 60 with relatively few events in women aged under 60 (table 1).

Of the predictor variables entered in the initial models, only flu, which was highly correlated with temperature, was dropped from all models. Temperature was dropped from the models for those aged under 60 and Christmas holidays from the model for men aged under 60 (table 2). We added first order autoregressive $\mathrm{AR}(1)$ terms to the final models for all people and for women aged 60 and over to allow for short term autocorrelation.

After the implementation of smoke-free legislation, there was a significant drop of $2.4 \%(\mathrm{P}=0.007)$ in the number of emergency admissions for myocardial infarction (table 2). This implies that just over 1200 emergency admissions for myocardial infarction were prevented over a 12 month period. Given that an initial myocardial infarction might result in several subsequent emergency admissions to hospital, this equates to around 1600 fewer emergency admissions. The subgroup analyses indicated that the legislation had an impact in men and women aged 60 and over, with a reduction of $3.07 \%(\mathrm{P}=0.001)$ and $3.82 \%(\mathrm{P}=0.007)$, respectively. Men aged under 60 also showed a signifi-
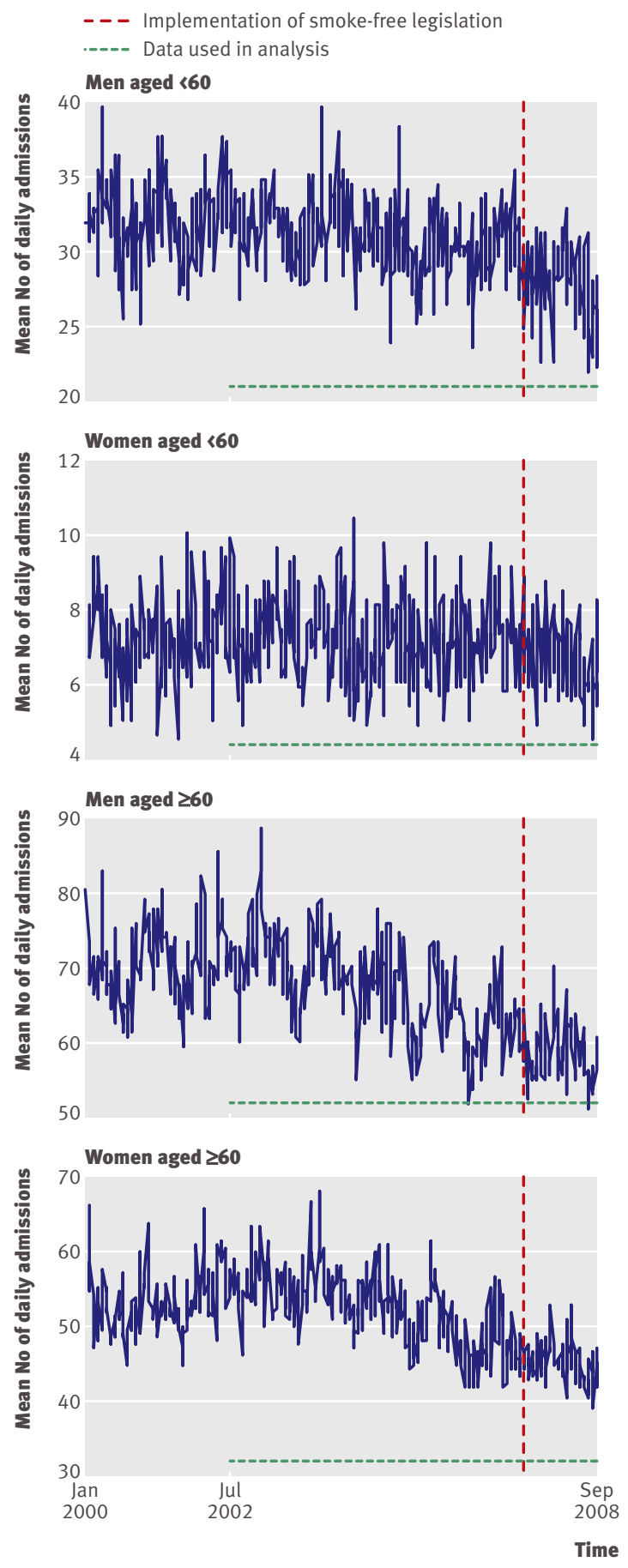

Fig 1 Trends in weekly number of emergency admissions for myocardial infarction (average daily count) from January 2000 to September 2008 by age and sex. Note different ranges on y axis 
Table 1| Number of emergency admissions* for myocardial infarction in England overall and by age group

\begin{tabular}{|c|c|c|c|c|c|}
\hline \multirow[b]{2}{*}{ Year beginning 1 July } & \multirow[b]{2}{*}{ All events } & \multicolumn{2}{|c|}{ Men } & \multicolumn{2}{|c|}{ Women } \\
\hline & & $<60$ & $\geq 60$ & $<60$ & $\geq 60$ \\
\hline 2002 & 61498 & 11704 & 26701 & 2746 & 20347 \\
\hline 2003 & 60680 & 11676 & 25841 & 2718 & 20445 \\
\hline 2004 & 58803 & 11448 & 24996 & 2635 & 19724 \\
\hline 2005 & 55752 & 10952 & 23679 & 2627 & 18494 \\
\hline 2006 & 53964 & 11075 & 22781 & 2636 & 17472 \\
\hline 2007 & 51664 & 10457 & 21824 & 2536 & 16847 \\
\hline
\end{tabular}

cant drop in admissions of $3.46 \%(\mathrm{P}<0.01)$, but the regression analysis gave no indication of a decline in younger women $(2.46 \%, \mathrm{P}=0.38)$. There was no evidence of a change in the slope of the trend line after the legislation.

By refitting the model with false dates for smoke-free legislation, we found that none of the false dates led to a significant impact in the population as a whole or in men of any age. In women aged over 60 , however, modelling with all but one of the false dates from the end of 2005 to 2007 yielded significant results.

\section{DISCUSSION}

Hospital admissions for myocardial infarction dropped significantly after the introduction of smokefree legislation in England. After adjustment for the pre-existing decline in admissions, trends in population size, and seasonal variation in admissions, we found a $2.4 \%$ drop in the number of emergency admissions for myocardial infarction after the legislation. This equates to 1200 fewer emergency admissions for myocardial infarction in the first year after the law came into effect (1600 including readmissions).

We identified a smaller reduction than other studies. We believe there are two main explanations for this. Firstly, exposure to secondhand smoke immediately before legislation was substantially lower in England than in other jurisdictions because of marked declines in population exposure in advance of the legislation. ${ }^{50}$

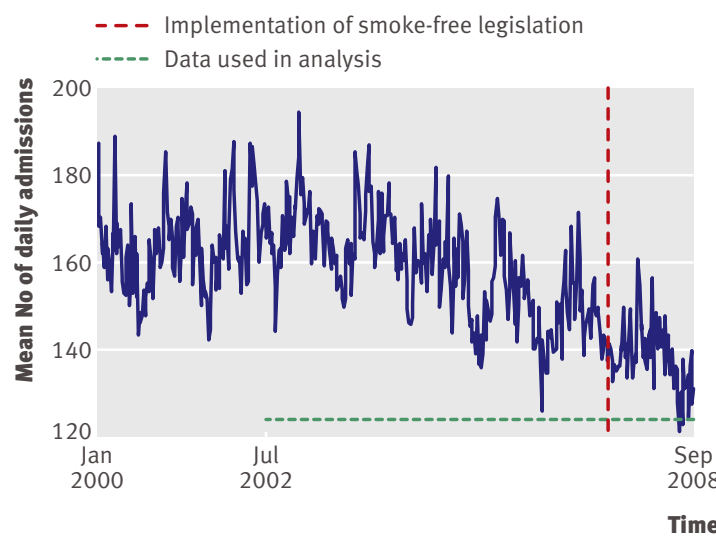

Fig 2 | Trends in overall weekly number of emergency admissions for myocardial infarction (average daily count) from January 2000 to September 2008. Note, weekly numbers of admissions are sum of four graphs in figure 1
Secondly, our study methods differed, with potentially better control of confounding.

Exposure before legislation

Smoke-free legislation in England was introduced at a time when many public places and workplaces were already smoke-free. In the year before implementation, a nationally representative survey (ONS Omnibus Survey) indicated that 55\% of employed adults in England already worked in a smoke-free environment. In addition, some bars and restaurants, the venues most affected by the legislation, went smoke-free before 1 July. Therefore, despite high compliance with the legislation, ${ }^{51}$ the decline in smoke exposure and the resulting health benefits of smoke-free legislation that occurred immediately after the implementation of legislation are likely to have been less marked than those observed elsewhere, making them harder to detect in a study such as this. A similar issue was noted in New York, where various pre-existing smoking restrictions were in place. ${ }^{21}$

Levels of exposure to secondhand smoke were around 50\% lower in England than in Scotland just before implementation of legislation in each country, whether measured by concentrations of particulate matter in bars $^{50}$ or cotinine concentrations (a biochemical marker of smoke exposure) in non-smoking bar workers ${ }^{50}$ and the general public. ${ }^{5253}$ While this might be partly explained by the introduction of legislation in England in summer and in Scotland in winter, the fact that the collection periods for the population data overlap in the two jurisdictions and that greater absolute declines in exposure were seen in Scotland suggest this cannot be the whole explanation.

Data on cotinine concentrations from population surveys indicates that population exposure to secondhand smoke in England has declined markedly since the mid-1990s. From 1993 to 2003 cotinine concentrations almost halved in non-smoking adults living with non-smoking partners and declined by a third in those living with smoking partners. ${ }^{54}$ In children, for whom more recent data on cotinine are available, there has been a 59\% decline in exposure between 1996 and 2006, with the largest annual decline in the year immediately before smoke-free legislation. ${ }^{55}$ If levels of exposure in adults have continued to decline, in line with those of children, some of the underlying decline in admissions to hospital for myocardial infarction 
Table $2 \mid$ Results of Poisson regression analyses to detect association between smoke-free legislation in England and emergency admissions for myocardial infarction

\begin{tabular}{|c|c|c|c|c|c|}
\hline \multirow[b]{2}{*}{ Final models* } & \multirow[b]{2}{*}{ All events } & \multicolumn{2}{|c|}{ Men } & \multicolumn{2}{|c|}{ Women } \\
\hline & & $<60$ & $\geq 60$ & $\ll 60$ & $\geq 60$ \\
\hline$\%$ change after smoke-free legislation $†$ ( $95 \% \mathrm{Cl}$ ) & $-2.37 \ddagger(-4.06$ to -0.66$)$ & $-3.46 \ddagger(-5.99$ to -0.85$)$ & $-3.07 \ddagger(-4.86$ to -1.25$)$ & $-2.46(-7.62$ to 3.00$)$ & $-3.82 \ddagger(-6.48$ to -1.09$)$ \\
\hline \multicolumn{6}{|l|}{ Other predictors kept in analysis: } \\
\hline Time (long term trend) & Yes & Yes & Yes & Yes & Yes \\
\hline Temperature§ & Yes & No & Yes & No & Yes \\
\hline Flu & No & No & No & No & No \\
\hline Christmas holidays & Yes & No & Yes & Yes & Yes \\
\hline Week of year & Yes & Yes & Yes & Yes & Yes \\
\hline \multicolumn{6}{|l|}{ Residuals: } \\
\hline AR(1) model & Yes & No & No & No & Yes \\
\hline
\end{tabular}

*All regression models were adjusted for population size, number of days, and smoke-free legislation.

†Calculated by exponentiating estimated regression coefficient for smoke-free legislation predictor.

$\ddagger \mathrm{P}<0.01$.

$\S$ In previous week.

before July 2007 is probably due to reductions in population exposure to secondhand smoke. Moreover, given that some of the decline in exposure is probably attributable to smoke-free legislation either indirectly (for example, through changes in behaviour triggered by growing public debates over secondhand smoke) or directly (public venues going smoke-free in advance of 1 July), studies such as this, designed to detect changes immediately after implementation, will underestimate impacts.

\section{Differences in methods}

The second explanation for the more modest decline found in our study relates to differences in methods. Several of the earlier studies used a "before and after" study design, and, although some used geographical controls, they might have been unable to fully account for underlying trends in admissions for myocardial infarction. Given the marked decline observed in admissions from 2002 onwards in our data, consistent with similar declines observed elsewhere, ${ }^{26-32}$ this might account for the greater reductions seen in such studies. Moreover, even if the before and after periods of these studies spanned the same months, bias from unseasonal weather patterns and fluctuations in the prevalence of other factors known to influence rates

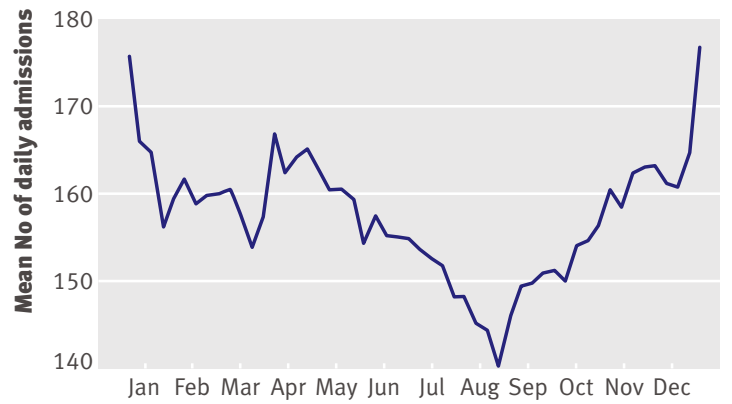

Month

Fig 3 | Trends in overall weekly number of emergency admissions for myocardial infarction (average daily count) averaged across years of coronary heart disease might have contributed to the changes observed. By accounting for the underlying decline in emergency admissions for myocardial infarction, seasonal patterns, and other risk factors (which few other studies have controlled for) ${ }^{39}$ we will produce a more conservative assessment of the contribution of smoke-free public places to reducing the number of emergency admissions. Although this might more accurately reflect the immediate impact of the implementation of the smoke-free law in England, for the reasons identified above, our estimate will miss the contribution of the legislation to the prelegislative declines in exposure to secondhand smoke and will thus underestimate its full impact.

\section{Validity and age, sex differences}

Although our reported impacts were significant $(\mathrm{P}<0.01$ in all but women aged under 60$)$, the confidence intervals were close to the null effect. There is, however, substantial reason for believing the decline in admissions is valid. It is biologically plausible, as outlined above, and robust to the "false dates" analysis in all but older women (discussed below). Moreover, when we imputed smoking prevalence and self reported data on exposure from the Health Survey for England $^{56}$ into a mathematical model developed by Richiardi et $\mathrm{al}^{57}$ to predict the impact of smoke-free legislation on admissions for myocardial infarction, the predicted reductions in admissions were between $3.6 \%$ and $10.9 \%$ in men and $2.4 \%$ and $7.2 \%$ in women. Our results are therefore consistent with the lower estimates obtained from the Richiardi model. ${ }^{57}$

Impacts were observed in men regardless of age, while in women we found a significant impact only among those aged 60 or over in whom some of the "false dates" also led to significant findings, indicating uncertainty around the impacts in this group. Although many studies do not examine impacts by sex, ${ }^{18-2137}$ the absence of an impact in women was also seen in Rome ${ }^{39}$ and in four other Italian regions. ${ }^{22}$ Three issues are worth considering here. Firstly, given that it was only the false dates during the 18 months before the 
legislation that were significant, this could suggest, in line with the issues raised above, that exposure to secondhand smoke was already declining in women and the false positives might therefore reflect a real, albeit gradual, reduction in myocardial infarction attributable to gradual declines in exposure. Secondly, both pre-legislative levels of, and reductions in, self reported exposure to secondhand smoke were lower in women than men. ${ }^{56}$ Thirdly, as a result of their low numbers of admissions, there was insufficient power in the analysis of women aged under 60 to detect the small impacts observed in men. Power calculations show that drops between $2-3 \%$ can be detected with high power $(80 \%)$ in all other population subgroups, but in women aged under 60 , only reductions greater than $7.5 \%$ could be detected with comparable power. As such, we can be confident only that there was no reduction greater than $7.5 \%$ in this subgroup. Whatever the reasons, the results in women must clearly be treated with caution.

\section{Limitations}

The main weakness of our study, common to most other studies on this topic, ${ }^{18-22242537-39}$ was that we relied on routine hospital data. Such data do not include the smoking status of patients, and we were therefore unable to determine how much of the decline after the legislation was attributable to reduced exposure to secondhand smoke and how much to reductions in active smoking. This is something we are currently investigating through analysis of another dataset.

Furthermore, definitions of and thresholds for diagnosing myocardial infarction have changed over time,${ }^{58}$ but the impact of this on routine records of hospital admissions is not fully understood. ${ }^{59} \mathrm{~A}$ redefinition of myocardial infarction occurred in 2000, wherein greater emphasis was placed on the use of specific biochemical markers (notably troponin). ${ }^{60}$ This was predicted to lead to an increase in the number of diagnosed myocardial infarctions, albeit on a gradual basis as the availability of troponin assays gradually increased. ${ }^{59}$ Although we observed no marked increase in admissions between 2000 and 2002 nor from 1997 to 2000 (data not shown), we chose to examine data from 2002 onwards to allow for any change in diagnostic threshold to take effect. In this way, and by including a linear predictor for time in our model, we hoped to capture any gradual change that might have occurred as best we could.

Reductions in hospital admissions for myocardial infarction might also be explained by increases in deaths from myocardial infarction outside hospital. Studies in Europe that have examined this issue, however, found a reduction in out of hospital deaths for coronary events accompanying the corresponding decline in admissions, ${ }^{2339}$ and this is therefore unlikely to be a concern.

Given that England was the last part of the UK to implement national smoke-free legislation (Scotland in March 2006, Wales and Northern Ireland in April 2007), an assessment of the impact compared with a control population with similar demographics was not feasible. But even if a control population had been available, confounding would not have been completely removed if an unusual event had occurred in only one population.

Aggregating individual admissions data to the national level meant we could consider only national level covariates. This prevented us from including local level covariates, such as temperature and air pollution, in the model. ${ }^{6162}$ Although this is unlikely to be a key concern for temperature given the high correlation documented between the Central England Temperature data series and the temperature at individual weather stations, ${ }^{63}$ it illustrates that residual confounding from unknown factors might remain. Finally, we were able to explore only the short term impact of the legislation, and it is possible that the impact on admissions for myocardial infarctions might vary over time, with two recent reviews suggesting that impacts could increase over time. ${ }^{1415}$

\section{Strengths}

Despite these concerns, we believe our study has several strengths and advantages over existing studies. With a population of 49 million (2001 census), England is the largest jurisdiction yet to go smoke-free. By using a comprehensive national dataset we were therefore able to provide a study population considerably larger than those of previous studies, which range from 19 million (New York State), ${ }^{21}$ through 2-5 million (New Zealand, ${ }^{24}$ parts of Italy, ${ }^{222539}$ and Scotland $\left.{ }^{23}\right)$, to less than 200000 (jurisdictions in $\mathrm{US}^{18-2038}$ and Canada ${ }^{37}$ ) and thus to offer greater statistical power to detect an impact in such a short time scale. We estimate that the smallest reduction detectable with a power of 0.8 , often considered the desirable level of power, is almost $2 \%$. This is important because other jurisdictions that, like England, have partial smoke-free restrictions in place before comprehensive legislation might be unable to detect changes this small because of their smaller populations and thus sample sizes. Furthermore, the robust segmented Poisson regression analysis, to a greater extent than most previous studies, was able to minimise confounding by accounting for underlying trends in population size and admissions for myocardial infarction and potential confounders such as season, temperature, flu, and holidays.

We therefore conclude that the implementation of smoke-free public places is associated with significant reductions in hospital admissions for myocardial infarction even in jurisdictions with pre-existing smoking restrictions. Given the large number of myocardial infarction events per year, even the relatively small reduction seen in England has important public health benefits.

We are grateful to the Association of Public Health Observatories, in particular Bobbie Jacobson, Paul Brown, and Davidson Ho for their support, and to the Health Protection Agency for providing the flu data. The HES data were made available by the NHS Health and Social Care Information Centre. We also thank Alan Kelly and Stephen Babb for their comments on early drafts of this paper. 


\section{WHAT IS ALREADY KNOWN ABOUT THIS TOPIC}

\section{Secondhand smoke increases the risk of acute myocardial infarction}

Studies from several countries have shown a reduction in hospital admissions for myocardial infarction after the implementation of smoke-free public places but many have failed to adequately account for potential confounders and underlying declines in admissions

\section{WHAT THIS STUDY ADDS}

Even after adjustment for potential confounders and secular trends, there was a small but significant reduction in hospital admissions for myocardial infarction after the introduction of smoke-free legislation in England

The smaller fall detected in England, compared with that observed elsewhere, probably reflects both the lower levels of exposure to secondhand smoke before the legislation and the fact that we accounted for underlying declines in admissions for myocardial infarction and other measurable confounders

Even a small relative decline in admissions for myocardial infarction can have important public health benefits given the prevalence of coronary heart disease

Contributors: AG developed the research proposal and is the principal investigator. AG and MS planned the analysis, drafted and edited the paper, and are guarantors. MS undertook the analysis. RM contributed to data preparation, study design, and editing of the paper. LB contributed to the funding proposal, drafting, and editing of the paper. Funding: This work was undertaken by the University of Bath, which received funding from the Department of Health's Policy Research Programme. The views expressed in the publication are those of the authors and not necessarily those of the Department of Health. AG is supported by a Health Foundation Clinician Scientist Fellowship. MS, LB, and $A G$ are members of the UK Centre for Tobacco Control, a UKCRC Public Health Research: Centre of Excellence. Funding from the British Heart Foundation, Cancer Research UK, Economic and Social Research Council, Medical Research Council and the Department of Health, under the auspices of the UK Clinical Research Collaboration is gratefully acknowledged. The funders played no role in the study design, analysis, and interpretation of data nor in the writing of the report or the decision to submit the article for publication.

Competing interests: All authors have completed the Unified Competing Interest form at www.icmje.org/coi_disclosure.pdf (available on request from the corresponding author) and declare that all authors had: (1) Financial support for the submitted work as detailed above; (2) No financial relationships with commercial entities that might have an interest in the submitted work; (3) No spouses, partners, or children with relationships with commercial entities that might have an interest in the submitted work; (4) No non-financial interests that may be relevant to the submitted work.

Ethical approval: The study was approved by the University of Bath School for Health's school research ethics approval panel (SREAP). Data sharing: No additional data available.

1 Glantz S, Parmley W. Passive smoking and heart disease: epidemiology, physiology, and biochemistry. Circulation 1991;83:1-12.

2 Glantz SA, Parmley WW. Passive smoking and heart disease: mechanisms and risk. JAMA 1995;273:1047-53.

3 He J, Vupputuri S, Allen K, Prerost MR, Hughes J, Whelton PK. Passive smoking and the risk of coronary heart disease-a meta-analysis of epidemiologic studies. N Engl J Med 1999;340:920-6.

4 Law MR, Morris JK, Wald NJ. Environmental tobacco smoke exposure and ischaemic heart disease: an evaluation of the evidence. BMJ 1997;315:973-80.

5 Thun M, Henley J, Apicella L. Epidemiologic studies of fatal and nonfatal cardiovascular disease and ETS exposure from spousal smoking. Environ Health Perspect 1999;107:841-6.

6 Wells A. Passive smoking as a cause of heart disease. J Am Coll Cardiol 1994;24:546-54.

7 Barnoya J, Glantz SA. Cardiovascular effects of secondhand smoke: nearly as large as smoking. Circulation 2005;111:2684-98.

8 Whincup PH, Gilg JA, Emberson JR, Jarvis MJ, Feyerabend C, Bryant A, et al. Passive smoking and risk of coronary heart disease and stroke: prospective study with cotinine measurement. BM/ 2004;329:200-5

9 Pechacek TF, Babb S. How acute and reversible are the cardiovascular risks of secondhand smoke? BMJ 2004;328:980-3.
10 Pope CA 3rd, Burnett RT, Krewski D, Jerrett M, Shi Y, Calle EE, et al. Cardiovascular mortality and exposure to airborne fine particulate matter and cigarette smoke. Shape of the exposure-response relationship. Circulation 2009;120:941-8.

11 Otsuka R, Watanabe H, Hirata K, Tokai K, Muro T, Yoshiyama M, et al. Acute effects of passive smoking on the coronary circulation in healthy young adults. JAMA 2001;286:436-41.

12 Dinno A, Glantz S. Clean indoor air laws immediately reduce heart attacks. Prev Med 2007;45:9-11.

13 Raupach T, Schafer K, Konstantinides S, Andreas S. Secondhand smoke as an acute threat for the cardiovascular system: a change in paradigm. Eur Heart / 2006;27:386-92.

14 Lightwood JM, Glantz SA. Declines in acute myocardial infarction after smoke-free laws and individual risk attributable to secondhand smoke. Circulation 2009;120:1373-9.

15 Meyers DG, Neuberger JS, He J. Cardiovascular effect of bans on smoking in public places: a systematic review and meta-analysis. J Am Coll Cardiol 2009;54:1249-55.

16 Institute of Medicine. Secondhand smoke exposure and cardiovascular effects: making sense of the evidence. National Academies Press, 2009.

17 IARC. IARC handbook of cancer prevention, tobacco control: evaluating the effectiveness of smoke-free policies. WHO, IARC, 2009.

18 Bartecchi C, Alsever RN, Nevin-Woods C, Thomas WM, Estacio RO, Bartelson BB, et al. Reduction in the incidence of acute myocardial infarction associated with a citywide smoking ordinance. Circulation 2006;114:1490-6.

19 Khuder SA, Milz S, Jordan T, Price J, Silvestri K, Butler P. The impact of a smoking ban on hospital admissions for coronary heart disease. Prev Med 2007;45:3-8.

20 Sargent RP, Shepard RM, Glantz SA. Reduced incidence of admissions for myocardial infarction associated with public smoking ban: before and after study. BMJ 2004;328:977-80.

21 Juster HR, Loomis BR, Hinman TM, Farrelly MC, Hyland A, Bauer UE, et al. Declines in hospital admissions for acute myocardial infarction in New York State after implementation of a comprehensive smoking ban. Am I Public Health 2007;97:2035-9.

22 Vasselli SPP, Gaelone D, Spizzichion L, De Campora E, Gnavt R, Saitto $C$, et al. Reduction incidence of myocardial infarction associated with a national legislative ban on smoking. Minerva Cardioangiol 2008;56:197-203.

23 Pell JP, Haw S, Cobbe S, Newby DE, Pell ACH, Fischbacher C, et al. Smoke-free legislation and hospitalizations for acute coronary syndrome. N Engl J Med 2008;359:482-91.

24 Edwards EBC, O’Dea D, Gifford H, Glover M, Laugesen M, Thomson G, et al. After the smoke has cleared: evaluation of the impact of a new smokefree law. New Zealand Ministry of Health, 2006.

25 Barone-Adesi F, Vizzini L, Merletti F, Richiardi L. Short-term effects of Italian smoking regulation on rates of hospital admission for acute myocardial infarction. Eur Heart J 2006;27:2468-72.

26 Koek HL, de Bruin A, Gast A, Gevers E, Kardaun JWPF, Reitsma JB et al. Decline in incidence of hospitalisation for acute myocardial infarction in the Netherlands from 1995 to 2000. Heart 2006;92:162-5.

27 MacIntyre K, Murphy NF, Chalmers J, Capewell S, Frame S, Finlayson A, et al. Hospital burden of suspected acute coronary syndromes: recent trends. Heart 2006;92:691-2.

28 Marques-Vidal P, Ruidavets J-B, Cambou J-P, Ferrieres J. Incidence, recurrence, and case fatality rates for myocardial infarction in southwestern France, 1985 to 1993. Heart 2000;84:171-5.

29 Murphy NF, MacIntyre K, Capewell S, Stewart S, Pell J, Chalmers J, et al. Hospital discharge rates for suspected acute coronary syndromes between 1990 and 2000: population based analysis. BMJ 2004;328:1413-4

30 O'Farrell AM, Bedford D, Howell F. Hospital discharge rates for acute coronary heart disease 1997-2002 in a health board region in Ireland: evidence of a shift in the pattern of presentation of the disease to acute hospitals. 2004. http://bmj.com/cgi/eletters/328/7453/1413\#62971.

31 Ford ES, Capewell S. Coronary heart disease mortality among young adults in the US from 1980 though 2002: concealed leveling of mortality rates. J Am Coll Cardiol 2007;50:2128-32.

32 Tu JV, Nardi L, Fang J, Liu J, Khalid L, Johansen H, et al. National trends in rates of death and hospital admissions related to acute myocardial infarction, heart failure and stroke, 1994-2004. CMA 2009;180:E118-25.

33 Crawford VLS, McCann M, Stout RW. Changes in seasonal deaths from myocardial infarction. O/ Med 2003;96:45-52.

34 Douglas AS, Dunnigan MG, Allan TM, Rawles JM. Seasonal variation in coronary heart disease in Scotland. J Epidemiol Community Health 1995;49:575-82.

35 Kloner RA. The "merry Christmas coronary" and "happy New Year heart attack" phenomenon. Circulation 2004;110:3744-5. 
36 Pell JP, Cobbe SM. Seasonal variations in coronary heart disease. $Q$ Med 1999;92:689-96.

37 Lemstra M, Neudorf C, Johnmark O. Implications of a public smoking ban. Revue Canadienne de Sante Publique 2008;99:62-5.

38 Seo Dong-Chul TMR. Reduced admissions for acute myocardial infarction associated with a public smoking ban: matched controlled study. J Drug Educ 2007;37:217-26.

39 Cesaroni G, Forastiere F, Agabiti N, Valente P, Zuccaro P, Perucci CA Effect of the Italian smoking ban on population rates of acute coronary events. Circulation 2008;117:1183-8.

40 O'Flaherty M, Bishop J, Redpath A, McLaughlin T, Murphy D, Chalmers J, et al. Coronary heart disease mortality among young adults in Scotland in relation to social inequalities: time trend study. BMJ 2009;339:b2613.

41 O'Flaherty M, Ford E, Allender S, Scarborough P, Capewell S. Coronary heart disease trends in England and Wales from 1984 to 2004: concealed levelling of mortality rates among young adults. Heart 2008;94:178-81.

42 NHS Information Centre for Health and Social Care. Hospital episode statistics online. 2010. www.hesonline.nhs.uk/Ease/servlet/ ContentServer?sitelD=1937.

43 World Health Organization. International statistical classification of diseases and related health problems. Tenth revision. WHO, 1992.

44 Wagner AK, Soumerai SB, Zhang F, Ross-Degnan D. Segmented regression analysis of interrupted time series studies in medication use research. J Clin Pharm Ther 2002;27:299-309.

45 UK Meteorological Office. Historical Central England temperature data. 2009. http://badc.nerc.ac.uk/data/cet/.

46 Parker DE, Legg TP, Folland CK. A new daily Central England temperature series, 1772-1991. Int J Climatol 1992;12:317-42.

47 Gemmell I, McLoone P, Boddy F, Dickinson G], Watt G. Seasonal variation in mortality in Scotland. Int J Epidemiol 2000;29:274-9.

48 Wood SN. Generalized additive models: an introduction with R. Chapman and Hall/CRC, 2006.

49 Akaike $\mathrm{H}$. Information theory and the extension of the Maximum Likelihood Principle. In: Petrov BN, Csaki F, eds. Second international symposium on information theory. Academia Kiado, 1973:267-81.

50 Semple S, van Tongeren M, Galea K, Maccalman L, Gee I, Parry O, et al. UK smokefree legislation: changes in PM2.5 concentrations in bars in Scotland, England and Wales. Ann Occup Hyg 2010; published online 19 February.

51 Department of Health. Smokefree England-one year on. Department of Health, 2009.

52 Haw SJ, Gruer L. Changes in exposure of adult non-smokers to secondhand smoke after implementation of smoke-free legislation in Scotland: national cross sectional survey. BMJ 2007;335:549-52.

53 Wardle H, Nicholson S, Mindell J, Craig R. The impact of smokefree legislation in England on cotinine levels in adults. Society for Social Medicine, 2009.
54 Royal College of Physicians. Going smoke-free: the medical case for clean air in the home, at work and in public places. A report by the Tobacco Advisory Group of the Royal College of Physicians. RCP, 2005.

55 Sims M, Tomkins S, Judge K, Taylor G, Jarvis MJ, Gilmore A. Trends in and determinants of second hand smoke exposure indexed by cotinine in children in England 1996-2006. Addiction 2010;105:543-53.

56 Wardle H, Mindell J. Adult cigarette smoking and exposure to others' smoke. In: Craig R, Shelton N, eds. Health Survey for England 2007. Vol 1: Healthy lifestyles: knowledge, attitudes and behaviour. National Centre for Social Research and the Department of Epidemiology at University College Medical School (London), 2008.

57 Richiardi L, Vizzini L, Maerletti F, Barone-Adesi F. Cardiovascular benefits of smoking regulations: the effect of decreased exposure to passive smoking. Prev Med 2009;48:167-72.

58 Fox KAA, Birkhead J, Wilcox R, Knight C, Barth J. British Cardiac Society Working Group on the definition of myocardial infarction. Heart 2004;90:603-9.

59 Luepker RV, Apple FS, Christenson RH, Crow RS, Fortmann SP, Goff D, et al. Case definitions for acute coronary heart disease in epidemiology and clinical research studies. A statement from: the AHA Council on Epidemiology and Prevention; AHA Statistics Committee; World Heart Federation Council on Epidemiology and Prevention; the European Society of Cardiology Working Group on Epidemiology and Prevention; Centers for Disease Control and Prevention; and the National Heart, Lung, and Blood Institute. Circulation 2003;108:2543-9.

60 Joint European Society of Cardiology/American College of Cardiology Committee. Myocardial infarction redefined-a consensus document of the Joint European Society of Cardiology/American College of Cardiology Committee for the Redefinition of Myocardial Infarction. Eur Heart / 2000;21:1502-13.

61 Peters A, Dockery DW, Muller JE, Mittleman MA. Increased particulate air pollution and the triggering of myocardial infarction. Circulation 2001;103:2810-15.

62 Pope CA 3rd, Burnett RT, Thurston GD, Thun MJ, Calle EE, Krewski D, et al. Cardiovascular mortality and long-term exposure to particulate air pollution: epidemiological evidence of general pathophysiological pathways of disease. Circulation 2004;109:71-7.

63 Croxton PJ, Huber K, Collinson N, Sparks TH. How well do the Central England temperature and the England and Wales precipitation series represent the climate of the UK? Int I Climatol 2006;26:2287-92.

Accepted: 11 February 2010 